\title{
Transcriptome analysis provides insights into the non-methylated lignin synthesis in Paphiopedilum armeniacum seed
}

\author{
Lin Fang ${ }^{1+}$, Xin $\mathrm{Xu}^{1,2+}{ }^{+}, \mathrm{Ji}_{\mathrm{Li}}{ }^{1,2}$, Feng Zheng ${ }^{1}$, Mingzhi Li ${ }^{3}$, Jingwei Yan ${ }^{4}$, Yuan $\mathrm{Li}^{1}$, Xinhua Zhang ${ }^{1}$, Lin Li ${ }^{1}$, \\ Guohua $\mathrm{Ma}^{1}$, Aying Zhang ${ }^{4}$, Fubing $\mathrm{Lv}^{5}$, Kunlin $\mathrm{Wu}^{1 *}$ and Songjun Zeng ${ }^{1,6^{*}}$
}

\begin{abstract}
Backgrounds: Paphiopedilum is an important genus of the orchid family Orchidaceae and has high horticultural value. The wild populations are under threat of extinction because of overcollection and habitat destruction. Mature seeds of most Paphiopedilum species are difficult to germinate, which severely restricts their germplasm conservation and commercial production. The factors inhibiting germination are largely unknown.

Results: In this study, large amounts of non-methylated lignin accumulated during seed maturation of Paphiopedilum armeniacum ( $P$. armeniacum), which negatively correlates with the germination rate. The transcriptome profiles of $P$. armeniacum seed at different development stages were compared to explore the molecular clues for non-methylated lignin synthesis. Kyoto Encyclopedia of Genes and Genomes (KEGG) enrichment analysis showed that a large number of genes associated with phenylpropanoid biosynthesis and phenylalanine metabolism during seed maturation were differentially expressed. Several key genes in the lignin biosynthetic pathway displayed different expression patterns during the lignification process. PAL, 4CL, HCT, and CSE upregulation was associated with $\mathrm{C}$ and $\mathrm{H}$ lignin accumulation. The expression of CCOAOMT, F5H, and COMT were maintained at a low level or down-regulated to inhibit the conversion to the typical $\mathrm{G}$ and $\mathrm{S}$ lignin. Quantitative real-time RT-PCR analysis confirmed the altered expression levels of these genes in seeds and vegetative tissues.
\end{abstract}

Conclusions: This work demonstrated the plasticity of natural lignin polymer assembly in seed and provided a better understanding of the molecular mechanism of seed-specific lignification process.

Keywords: Paphiopedilum armeniacum, Lignin, Transcriptome analysis, Germination

\section{Background}

Paphiopedilum Pftzer (Orchidacease) is commonly known as Lady's slipper orchid because of its slippershaped pouch. Members of this genus have high ornamental value because the flowers are uniquely shaped and come in a wide variety of colors and sizes. Despite their horticultural value, wild populations of Paphiopedilum are

\footnotetext{
* Correspondence: wkl8@scib.ac.cn; zengsongjun@scib.ac.cn

${ }^{+}$Lin Fang and Xin Xu contributed equally to this work.

'Guangdong Provincial Key Laboratory of Applied Botany, South China Botanical Garden, Chinese Academy of Sciences, Guangzhou 510650, China Full list of author information is available at the end of the article
}

under threats of extinction due to overcollection and habitat destruction. As a result, all species are listed in the Convention on International Trade in Endangered Species of Wild Fauna and Flora (CITES) Appendix I which also prohibit their trade [1].

Many orchid seeds including Paphiopedilum are tiny and contain no endosperm. In contrast, most angiosperm seeds have well-developed embryos. Paphiopedilum seeds are generally unable to germinate on their own. They form a mycorrhizal relationship that help with the nourishment of emerging seedling [2, 3]. Even

(c) The Author(s). 2020 Open Access This article is licensed under a Creative Commons Attribution 4.0 International License, which permits use, sharing, adaptation, distribution and reproduction in any medium or format, as long as you give appropriate credit to the original author(s) and the source, provide a link to the Creative Commons licence, and indicate if changes were made. The images or other third party material in this article are included in the article's Creative Commons licence, unless indicated otherwise in a credit line to the material. If material is not included in the article's Creative Commons licence and your intended use is not permitted by statutory regulation or exceeds the permitted use, you will need to obtain permission directly from the copyright holder. To view a copy of this licence, visit http://creativecommons.org/licenses/by/4.0/. The Creative Commons Public Domain Dedication waiver (http://creativecommons.org/publicdomain/zero/1.0/) applies to the data made available in this article, unless otherwise stated in a credit line to the data. 
with the additional nutrients, mature seeds of most Paphiopedilum species still have difficulty germinating, which severely restricts their conservation and largescale production. However, the factors inhibiting germination are still unknown. Paphiopedilum seeds develop heavily lignified secondary cell walls to provide mechanical support and prevent permeability to water and nutrients $[4,5]$. This feature enhances the survival of orchid seeds in harsh conditions. However, several studies imply that the accumulation of lignin contributes to the inhibition of germination during aseptic germination $[6,7]$. Immature orchid seeds with low degree of lignification were shown to exhibit higher germination rates than mature seed with higher lignification $[2,8]$. Mature seeds subjected to lignin degradation resulted in enhanced germination rates [2, 6, 9]. Based on these findings, it is possible that the high amounts of lignin act as germination inhibitors.

Lignin is a phenolic polymer formed by oxidative polymerization of the primary hydroxycinamyl alcohols (monolignols), $\rho$-coumaryl, caffeyl, coniferyl, sinapyl, and 5-hydroxylcinnamyl alcohols that give rise to $\rho$ hydroxylphenyl $(\mathrm{H})$, catechyl $(\mathrm{C})$, guaiacyl $(\mathrm{G})$, syringyl (S), and 5-hydroxyguaiacyl (5H/5-OH-G) lignin. The five monolignols differ by their degree and position of methoxylation. The $\mathrm{H}$ and $\mathrm{C}$ units are non-methoxylated, whereas the $\mathrm{G}$ and $5 \mathrm{H}$ units have a single methylation on the 3-hydroxyl group and the $\mathrm{S}$ subunit is methylated on both the 3- and 5-hydroxyl moieties [10]. Lignin composition varies among plant species and tissue types. Lignins found in the vascular tissues are mainly composed of $\mathrm{G}$ and $\mathrm{S}$ units. However, seed lignins have a significant variation in monolignol compositions. Seed of certain species belonging to Orchidaceae, Cactaceae, Cleomaceae, and Euphorbiaceae contain lignin with the typical H, G, and $S$ units, as well as $C$ unit [11-13]. The significance of these variations remain unknown. The non-methylated monolignols are incorporated into lignin polymers via benzodioxane bonds, forming a linear structure without side chains $[14,15]$. The linear lignin has less crosslinking with other cell wall components and is capable of enhancing the hydrophobicity and stability of the plant tissue [16]. The lignin biosynthesis pathway is well established, involving O-methyltransferases (CCoAOMT and COMT) to generate monolignols differing in their degree of methylation [10]. Disruption or downregulation of these genes can lead to changes in lignin composition, resulting in changes to cell wall integrity and mechanical properties of the tissue $[17,18]$.

The seeds of Paphiopedilum armeniacum (P. armeniacum) contain non-methoxylated $\mathrm{H}$ and $\mathrm{C}$ lignin. The deposition of non-methylated lignin begins in the early stages of seed development of $P$. armeniacum and eventually makes up approximately $39 \%$ of the total seed dry mass. Despite its unique structure and potentially important function, the biosynthesis of lignins in plant seeds has received little attention relative to that of vascular tissues. In this study, a detailed gene expression profiling was performed at five key developmental stages of $P$. armeniacum seeds to help elucidate the seedspecific regulation of lignin biosynthesis.

\section{Results}

\section{Embryo developmental features and lignin accumulation} during seed development

Zygotic embryos of $P$. armeniacum began to develop at 45 days after pollination (DAP) as previously described [3]. At 66 DAP, the T-shaped pre-embryo with four cells was formed (Table 1). At 87 DAP, the globular embryo was formed. Around 108 DAP, there is a rapid lignification of the seed coat, the inner testa disappears, and lipid globule and starch accumulate. At $122 \mathrm{DAP}$, the embryo is fully mature with a compact testa and no further observed morphological changes. Five developmental stages $(66,87,108,122$, and $150 \mathrm{DAP})$ of $P$. armeniacum embryos were selected for further lignin structure characterization and transcriptome profiles on the basis of lignin accumulation pattern and embryo developmental characteristics.

The germination was scored together with the lignin content during the seed development (Fig. 1a). During the early stages of seed development (45-95 DAP), the germination rate gradually increased as the embryo formation. At 95 DAP, the globular embryo has been fully developed, and the germination rate reached $96.2 \%$. During this stage, lignin was maintained at a relatively low level (5-9\% of the dry mass). After that, even though the starch and lipid globules continue to accumulate as described in a previous study [3], the germination rate dropped sharply from 96 to $5 \%$. Meanwhile, the amounts of lignin started to increase rapidly, with the seed coat changing from white to brown (Fig. 1b). Lignin accumulation reached a plateau ( $39 \%$ of the dry mass) at 150 DAP, with the seed coats becoming dark and hard.

\section{Identification of non-methylated lignin in seeds}

To analyze the monolignol composition from various tissue types, the samples were subjected to pyrolysis-gas chromatography/ mass spectrometry (Py-GC/MS). The identities and relative molar abundances of the released compounds are listed in Table 2. The results showed that the lignin in the seeds contain high levels of $\mathrm{C}$ units and $\mathrm{H}$ units without any traces of $\mathrm{G}$ and $\mathrm{S}$ units. In contrast, lignins present in other tissues (stems, leaves, and pods residues after seed isolation) were composed mainly of $\mathrm{G}$ and $\mathrm{S}$ units with essentially no $\mathrm{C}$ units.

The composition of monolignol structure in seeds was further characterized for the assignments for $\mathrm{C}$ lignin 
Table 1 Characteristics of the developing seeds of P.armeniacum after pollination

\begin{tabular}{|c|c|c|c|c|c|c|}
\hline$\overline{D A P}$ & Developmental status & Seed color & $\begin{array}{l}\text { Germination } \\
\text { percentage (\%) }\end{array}$ & $\begin{array}{l}\text { Lignin } \\
\text { content }(\%)\end{array}$ & $\begin{array}{l}\text { ABA content } \\
\mathrm{ng} / \mathrm{g} \mathrm{FW}\end{array}$ & Water content (\%) \\
\hline 66 & T-shaped pre-embryo with four cells & Yellowish white & $5.0 \pm 0.2$ & $6.0 \pm 0.3$ & $5.6 \pm 2.7$ & $87.0 \pm 4.3$ \\
\hline 87 & $\begin{array}{l}\text { The globular embryo forms, and the outside-layer } \\
\text { cells of the outer integument begin to dehydrate } \\
\text { and the suspensor starts to degenerate }\end{array}$ & Yellowish white & $44.0 \pm 5.5$ & $5.0 \pm 0.9$ & $6.5 \pm 2.1$ & $79.8 \pm 2.1$ \\
\hline 108 & $\begin{array}{l}\text { The inner testa disappears, and starch and lipid } \\
\text { globules accumulate rapidly }\end{array}$ & $\begin{array}{l}\text { A mixture of yellow } \\
\text { and light brown }\end{array}$ & $66.0 \pm 5.2$ & $13.0 \pm 3.5$ & $9.0 \pm 2.2$ & $72.2 \pm 1.1$ \\
\hline 122 & $\begin{array}{l}\text { The embryo is fully mature with a compact testa } \\
\text { and no further morphological changes }\end{array}$ & Brown dark & $37.0 \pm 7.2$ & $22.0 \pm 4.1$ & $14.4 \pm 3.1$ & $68.6 \pm 2.6$ \\
\hline 150 & Dry and mature seeds & Dark & $10.0 \pm 1.7$ & $39.0 \pm 5.45$ & $1.4 \pm 0.2$ & $51.5 \pm 0.6$ \\
\hline 180 & Dry and mature seeds & Dark & $5.0 \pm 0.75$ & $37.0 \pm 3.56$ & $2.3 \pm 1.2$ & $49.2 \pm 0.7$ \\
\hline
\end{tabular}

and G/S lignin in Fourier transform infrared spectroscopy (FTIR) and Nuclear Magnetic Resonance (NMR) spectra in orchid seeds as previously established [1113]. FTIR spectra from the seeds at five developmental stages indicated $C$ lignin deposited in the early stage with distinct $C$ lignin bands at $1154 \mathrm{~cm}^{-1}$ and $823 \mathrm{~cm}^{-1}$ (Fig. 2a). The rapid development of the two bands was observed at 108 DAP. In agreement with Py-GC/MS analysis, no typical G/S lignin was detected in $P$. armeniacum seeds during the five developmental stages. Analysis of the aromatic region of the 2D NMR spectra of mature seeds confirmed the presence of $\mathrm{H}$ and $\mathrm{C}$ lignin
(Fig. 2b). The results indicated that the monolignol composition varied among tissue types in P. armeniacum, and that the non-methylated $\mathrm{C}$ lignin and $\mathrm{H}$ lignin specifically deposited in the seed.

\section{RNAseq analysis, de novo assembly, and functional annotation}

RNA-seq analysis of $P$. armeniacum seeds was performed at five developmental stages (66, 87, 108, 122, and $150 \mathrm{DAP})$ to characterize the transcriptome dynamics of $P$. armeniacum seed development and to identify genes involved in the seed-specific lignification. Three

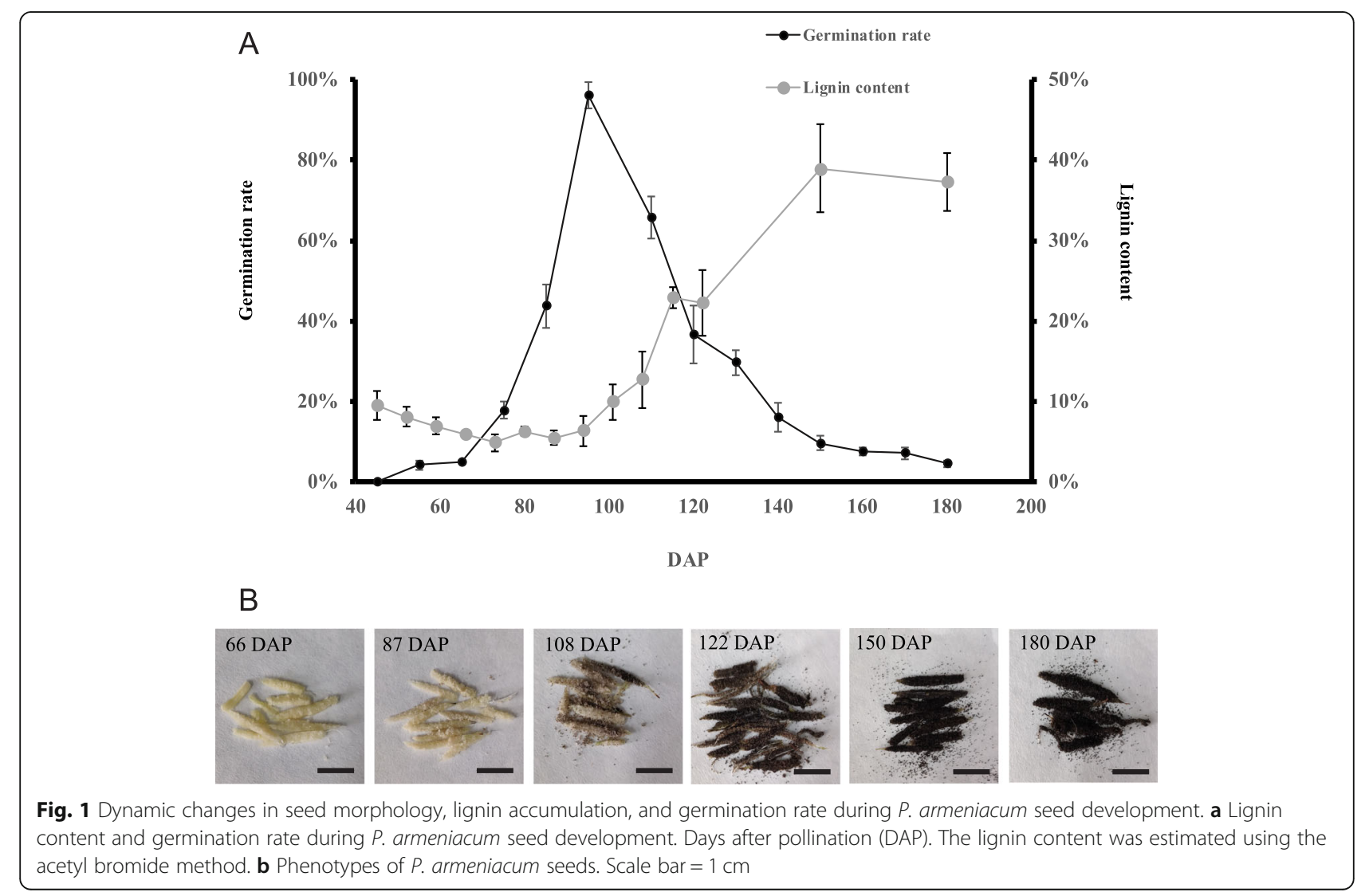


Table 2 Relative molar abundances (\%) of the compounds released after pyro-GC/MS of seeds, stems, leaves and pods of $P$. armeniacum. Values in brackets are the standard deviations from three biological replicates

\begin{tabular}{|c|c|c|c|c|c|c|c|c|}
\hline Compound name & Origin & Formula & Molecular Mass & Main Mass fragments & Seeds (\%) & Stems (\%) & Leaves (\%) & Pods (\%) \\
\hline Phenol & $\mathrm{H}$ & $\mathrm{C}_{6} \mathrm{H}_{6} \mathrm{O}$ & 94 & $65,66,94$ & $16.2(0.1)$ & - & $23.0(6.9)$ & $\overline{5.7(1.2)}$ \\
\hline 2-Methylphenol & $\mathrm{H}$ & $\mathrm{C}_{7} \mathrm{H}_{8} \mathrm{O}$ & 108 & $77,107,108$ & $18.7(0.4)$ & - & - & - \\
\hline 3-Methylphenol & $\mathrm{H}$ & $\mathrm{C}_{7} \mathrm{H}_{8} \mathrm{O}$ & 108 & $77,107,108$ & $18.3(0.4)$ & - & - & - \\
\hline 2,5-Dimethylphenol & $\mathrm{H}$ & $\mathrm{C}_{8} \mathrm{H}_{10} \mathrm{O}$ & 122 & $77,107,122$ & $7.2(1.3)$ & - & - & - \\
\hline Catechol & C & $\mathrm{C}_{6} \mathrm{H}_{6} \mathrm{O}_{2}$ & 110 & $53,64,110$ & $19.6(2.7)$ & - & - & - \\
\hline 4-Methylcatechol & C & $\mathrm{C}_{7} \mathrm{H}_{8} \mathrm{O}_{2}$ & 124 & $51,97,125$ & $13.4(0.7)$ & - & - & - \\
\hline 4-Ethylcatechol & $C$ & $\mathrm{C}_{8} \mathrm{H}_{10} \mathrm{O}_{2}$ & 138 & $51,78,124$ & $6.5(0.1)$ & - & - & - \\
\hline 2-Methoxylphenol & G & $\mathrm{C}_{7} \mathrm{H}_{8} \mathrm{O}_{2}$ & 124 & $81,109,124$ & - & $14.9(0.8)$ & $16.1(2.1)$ & $19.0(2.1)$ \\
\hline 2-Methoxy-5-methylphenol & G & $\mathrm{C}_{8} \mathrm{H}_{10} \mathrm{O}_{2}$ & 138 & $95,123,138$ & - & $5.6(0.2)$ & - & $13.4(2.7)$ \\
\hline 4-Ethenyl-2-methoxyphenol & G & $\mathrm{C}_{9} \mathrm{H}_{10} \mathrm{O}_{2}$ & 150 & $107,135,150$ & - & $31.6(4.6)$ & $23.1(3.2)$ & $31.7(3.2)$ \\
\hline 4-Hydroxy-3-methoxybenzaldehyde & G & $\mathrm{C}_{8} \mathrm{H}_{8} \mathrm{O}_{3}$ & 152 & $109,151,152$ & - & $4.5(0.1)$ & - & $5.5(0.3)$ \\
\hline 2-Methoxy-4-propenylphenol & G & $\mathrm{C}_{10} \mathrm{H}_{12} \mathrm{O}_{2}$ & 164 & $131,149,164$ & - & $7.9(0.1)$ & - & $11.2(0.6)$ \\
\hline 4-Hydroxy-3-methoxyphenyl acetone & G & $\mathrm{C}_{10} \mathrm{H}_{12} \mathrm{O}_{3}$ & 180 & $122,137,180$ & - & $4.1(0.3)$ & $18.1(0.7)$ & - \\
\hline 2,6-Dimethoxyphenol & S & $\mathrm{C}_{8} \mathrm{H}_{10} \mathrm{O}_{3}$ & 154 & $111,139,154$ & - & - & $19.8(4.7)$ & $13.6(2.6)$ \\
\hline 4-Hydroxy-3,5-dimethoxystyrene & S & $\mathrm{C}_{10} \mathrm{H}_{12} \mathrm{O}_{3}$ & 180 & $137,165,180$ & - & $31.6(2.7)$ & - & - \\
\hline$\% \mathrm{H}$ units & & & & & $60.5(2.0)$ & - & $23.0(4.3)$ & $5.7(0.9)$ \\
\hline$\%$ C units & & & & & 39.5 (2.0) & - & - & - \\
\hline$\%$ G units & & & & & - & $68.4(6.9)$ & $57.2(3.1)$ & $80.7(2.5)$ \\
\hline$\%$ S units & & & & & - & $31.6(2.1)$ & $19.8(2.9)$ & $13.6(1.9)$ \\
\hline
\end{tabular}

biological replicate sequencing libraries were prepared from each stage. A total of $104.12 \mathrm{~Gb}$ clean data were generated from each library after filtering out lowquality data. The transcriptome details for each sample are shown in Table S1. Q30 of the raw data ranged from 92.10 to $94.11 \%$ indicating high-quality reads worthy of further analysis. Since no reference genome is available for Paphiopedilum, a de novo assembly of all 347,075, 856 reads into 433,854 transcripts with an N50 length of $1180 \mathrm{bp}$ and 183,737 unigenes with an average length of $860 \mathrm{bp}$. The transcripts and unigenes length distribution are shown in Table S2. The biological reproducibility was assessed using the Pearson's correlation coefficient, which showed that the correlation between samples among the same biological replicates was high (Fig. S1A). Principle component analysis (PCA) of all samples during seed development was also performed (Fig. S2B). Consistent with their distinct developmental stages, samples from different biological replicates were clustered separately.

For annotation, 183,737 unigenes were subjected to BLASTX searches against the sequences in the NCBI non-redundant protein sequences (NR), Swissprot, Gene Ontology (GO), the Clusters of Orthologous Groups (COG), and Kyoto Encyclopedia of Genes and Genomes (KEGG) databases. As a result, a total of 92,235 unigenes (50.20\% of all unigenes) could be assigned at least one putative function from one of these databases (Table S3). A total of 89,285 unigenes were annotated from the NR database. Further analysis of the matched sequences showed that the $P$. armeniacum transcript was highly similar to Dendrobium catenatum (29.86\%), Apostasia shenzhenica (8.38\%), and Phalaenopsis equestris (5.45\%) as shown in Fig. S2A. For GO annotation, a total of 29,301 unigenes from $P$. armeniacum seeds were annotated into three GO pathways, as shown in Fig. 3b. The functions of unigenes in biological process classifications contained cellular process, metabolic process, and biological regulation. Cell part, cell, and organelle were the most abundant functions in terms of cellular component classifications. The most abundant biological process functions are metabolic process and cellular process. In the molecular function classification, binding and catalytic activity were more abundant. The main GO entries were consistent with the fact that the cells divided frequently during seed development. Other entries such as catalytic, metabolic and binding activities were relatively high.

\section{Differential gene expression and KEGG enrichment analysis}

With the restrictive conditions of False Discovery Rate $($ FDR $)<0.05$ and $\log 2$ ratio $\geq 1.0$, unigenes that were differentially expressed in the seeds at the five developmental stages were identified. In total 8722 differentially 


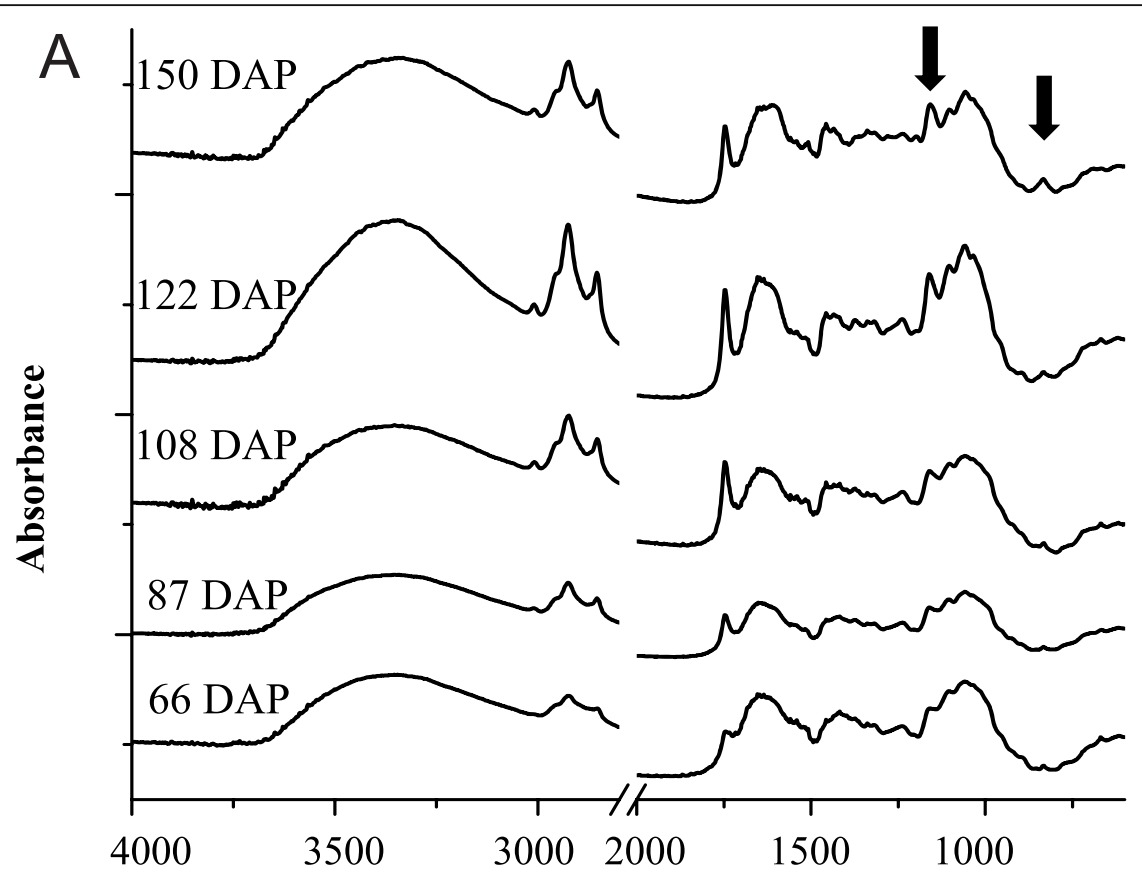

Waveno $/ \mathbf{c m}^{-1}$

B

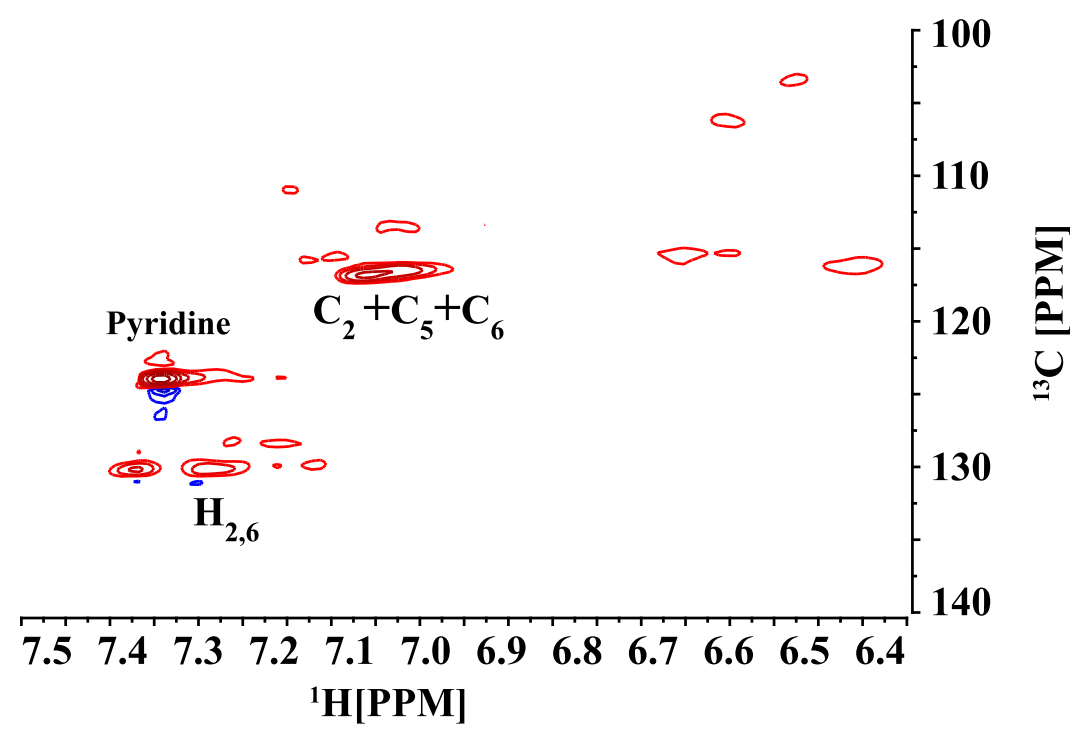

Fig. 2 Lignin structure characterization. a FTIR spectra of P. armeniacum seeds at five developmental stages. Positions of C lignin bands are marked by arrows. b Partial short-range ${ }^{13} \mathrm{C}^{1} \mathrm{H}$ (HSQC) spectra (aromatic region) of 122 DAP mature seeds

expressed genes (DEGs) were identified among all the libraries. The number of DEGs increased with seed development and peaked among 122 DAP and 66 DAP seeds (Fig. 3a). A total of 576 common DEGs were identified in 87 DAP, 108 DAP, 122 DAP, and 150 DAP among all developmental stages, implying that these DEGs might be associated with seed development (Fig. 3b).

KEGG enrichment analysis with the DEGs in 87 DAP vs 66 DAP, 108 DAP vs 66 DAP, 122 DAP vs 66 DAP, and 150 vs 66 DAP (Fig. 4 and Table S4) were 

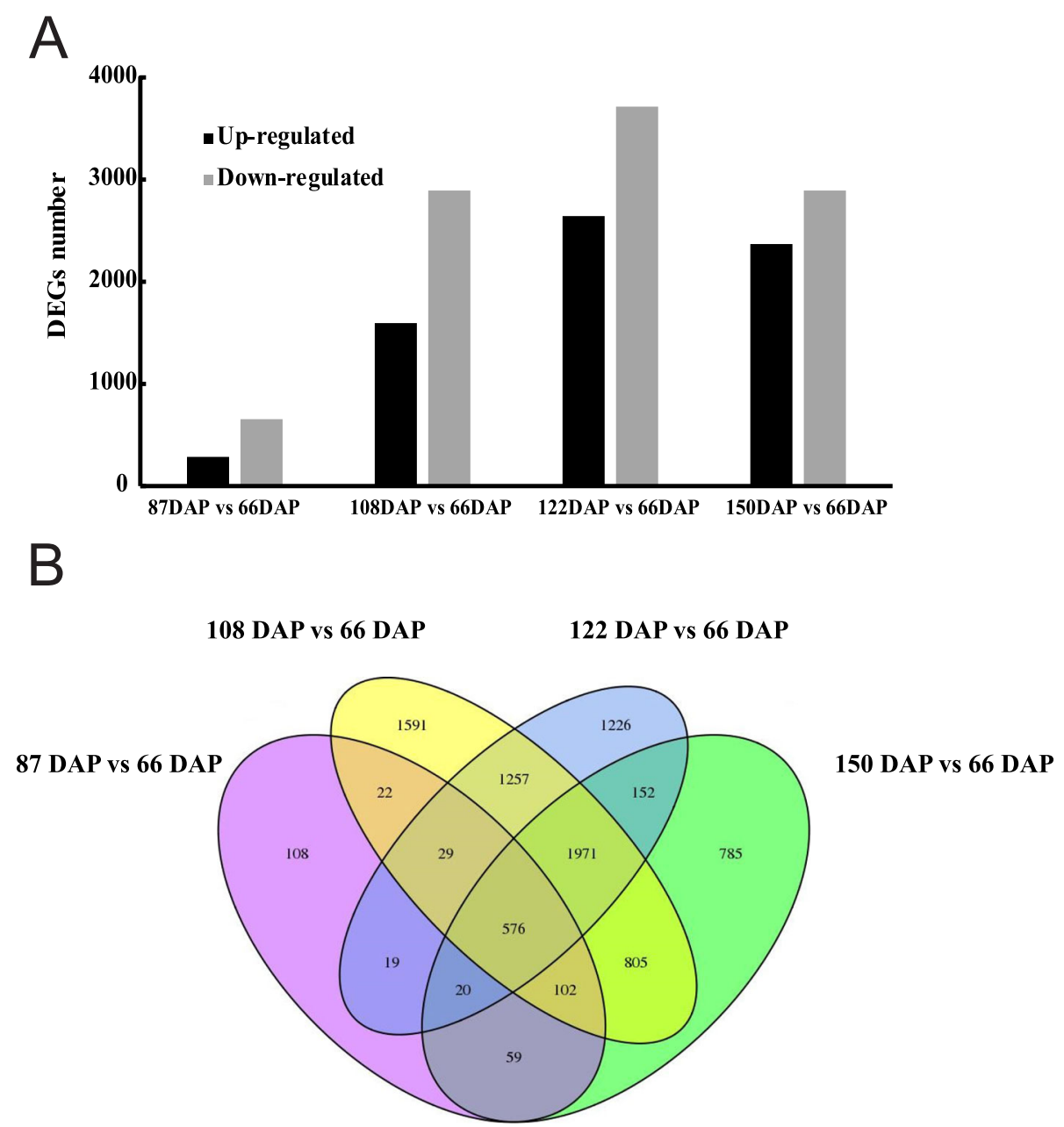

Fig. 3 Statistical analysis of differentially expressed unigenes (DEGs) during P. armeniacum seed development. a Up/down-regulated unigenes in all development stages. The total DEG number peaked between 122 DAP and 66 DAP. b Venn diagram of all DEGs

performed to provide more insight into the DEGs regulating lignin deposition at the later stages of seed development. The top-enriched KEGG pathways of these DEGs were secondary metabolite biosynthesis pathways, including flavonoid, phenylpropanoid and flavone, and flavonol biosynthesis pathways, etc. Among them, flavone and flavonol biosynthesis (ko00944) and flavonoid biosynthesis (ko00941) are highly enriched throughout the five key developmental stages, suggesting these pathways are potentially important for seed development such as with pigment accumulation, but not specifically related to lignin deposition. Our premise is that genes involved in non-methylated lignin accumulation would be induced primarily during the lignin rapid accumulation stage (from 101 DAP to 150 DAP). The analysis showed that phenylpropanoid biosynthesis (ko00940) and phenylalanine metabolism (ko00360) are indeed highly enriched in 108 DAP vs 66DAP, 122DAP vs 66DAP, and 150 vs 66DAP. Other highly enriched pathways were DNA replication (ko03030) in 87DAP vs 66DAP, starch and sucrose metabolism (ko00500) in 87DAP vs $66 \mathrm{DAP}$ and $108 \mathrm{DAP}$ vs $66 \mathrm{DAP}$, and plant hormone signal transduction (ko04075) in 150DAP vs 66DAP.

\section{Identification of genes potentially involved in non- methylated lignin biosynthesis}

The monolignol biosynthesis pathway is well established, and a series of enzymatic reactions catalyzed by specific enzymes have been identified, including phenylalanine ammonia lyase (PAL), cinnamic acid 4-hydroxylase $(\mathrm{C} 4 \mathrm{H})$, 4-coumarate: CoA ligase (4CL), cinnamoyl-CoA reductase (CCR), cinnamyl alcohol dehydrogenase (CAD), hydroxycinnamoyl CoA: shikimate hydroxycinnamoyl transferase (HCT), 4-coumarate 3-hydroxylase $(\mathrm{C} 3 \mathrm{H})$, caffeoyl shikimate esterase (CSE), ferulic acid 5-hydroxylase (F5H), caffeic acid O-methyltransferase (COMT), and caffeoyl-CoA 3-O-methyltransferase (CCoAOMT) [10, 15] (Fig. 5). The 


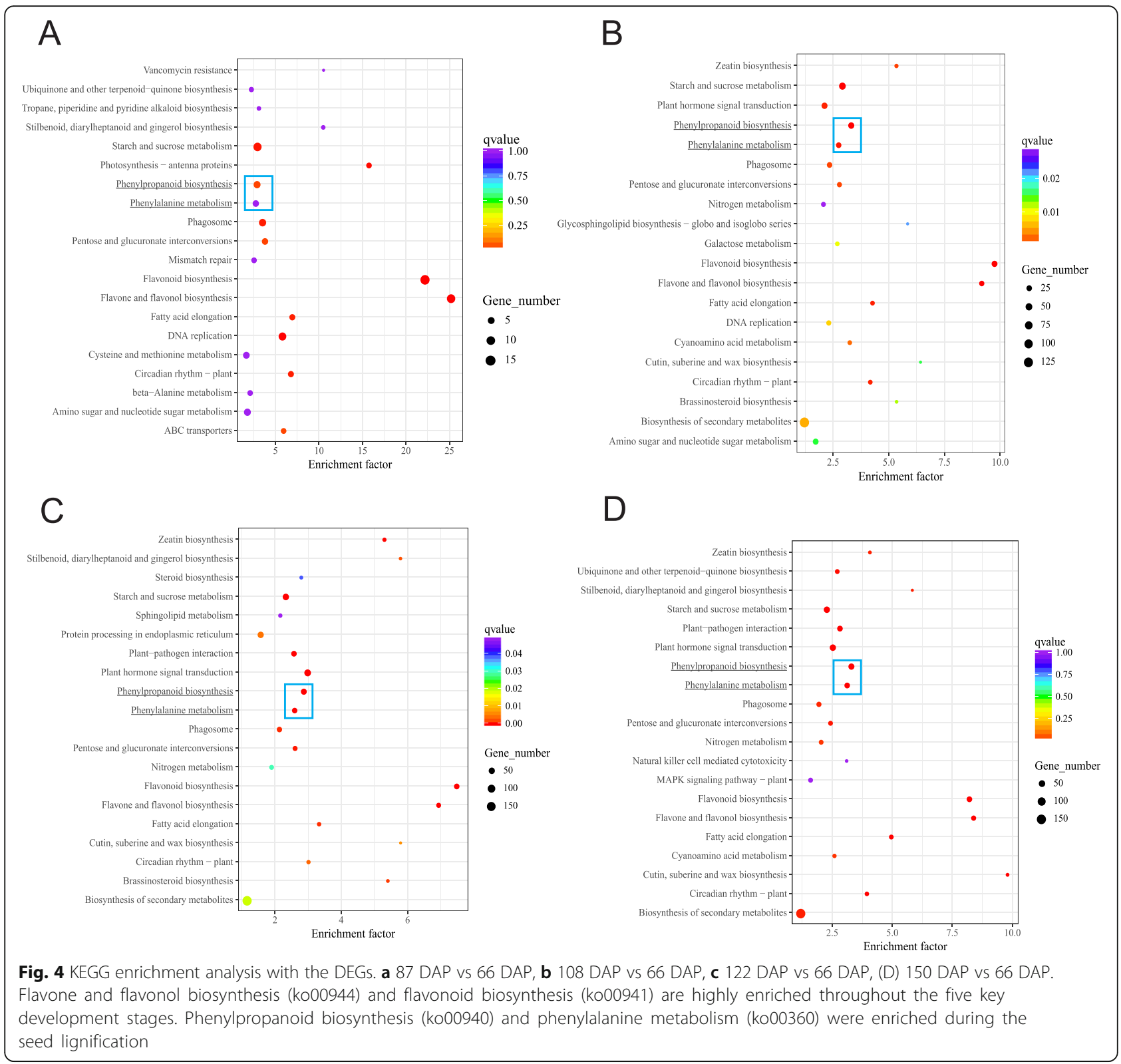

annotated lignin pathway gene in the KEGG database identified 20 Paphiopedilum genes that are homologous to genes potentially involved in monolignol synthesis (Table S5). Phylogenetic trees for the individual protein families of Arabidopsis, Dendrobium, and Phalaenopsis were constructed using the CDS sequenced listed in Table S10. The results showed that the identified genes in lignin biosynthetic pathways had a close genetic relationship with those reported in other plant species (Fig. 6).

Most lignin-related genes displayed a very similar transcript level between 66 DAP and 87 DAP, prior to the rapid accumulation of lignin (Figs. 6 and 7). Several monolignol synthesis related genes $P A L, 4 C L, H C T$, and
CSE demonstrated increased expression levels from 87 DAP to 150 DAP. Despite the high expression levels of these genes, most CCOAOMT, COMT, and $F 5 H$ were absent or down-regulated from developing seeds, and a few displayed a significant decrease in the expression level. CCOAOMT expression level is relatively high at $66 \mathrm{DAP}$, but the low expression level of $F 5 H$ made the conversion of caffeoyl moieties to feruloyl moieties inefficient, which resulted in no $\mathrm{G}$ and $\mathrm{S}$ lignin production at the early stage of the seed development. Later, the decrease in the expression level of CCOAOMT and upregulation of upstream genes in monolignol pathway caused the accumulation of $\mathrm{H}$ and $\mathrm{C}$ lignins instead of $\mathrm{G}$ and $\mathrm{C}$ lignins. 


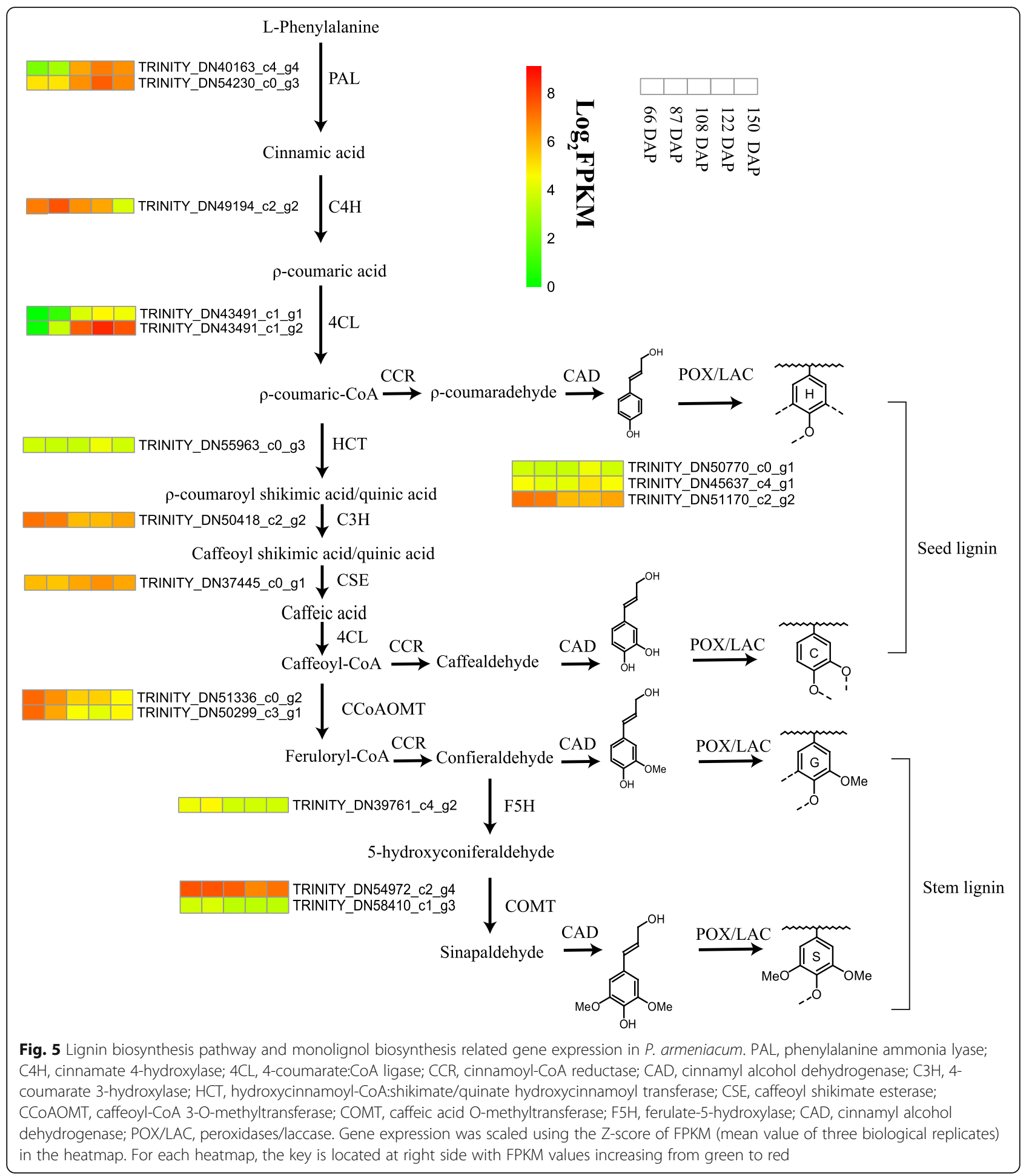

qRT-PCR validation of candidate genes involved in lignin biosynthesis

Contigs corresponding to PAL, 4CL, HCT, C4H, CCOAOMT, F5H, and COMT in five development stages of seed development were selected for qRT-PCR validation to verify the accuracy and reproducibility of the
RNA-seq results. Methylated lignin-rich tissue stems were also included to verify our predicted monolignol pathway. The sequences of the primers used are given in Table S6. Reliable estimation of gene expression by qRT-PCR requires stable reference genes for data normalization. Six housekeeping genes ACTIN1, ACTI 


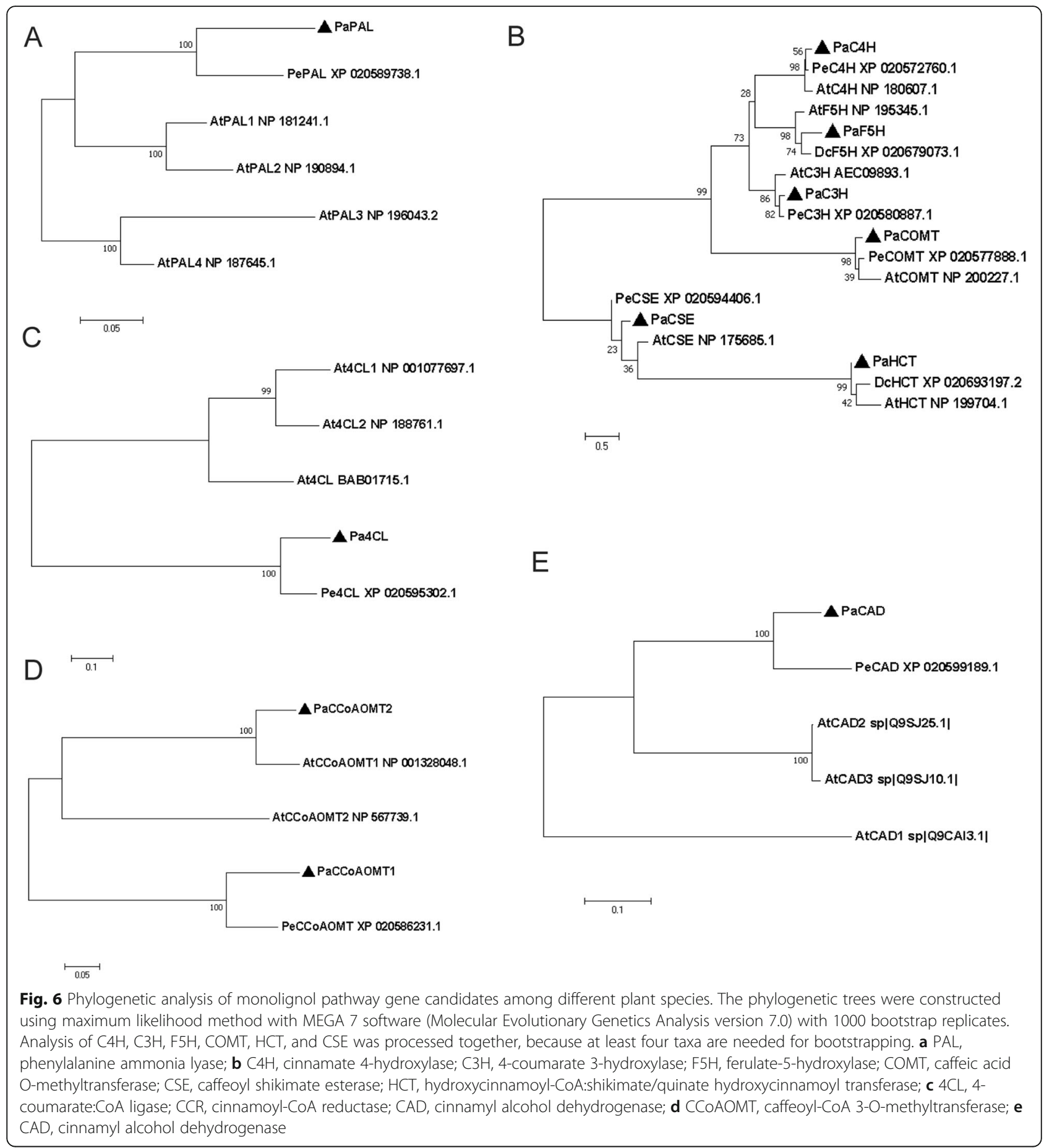

N2, TUBLIN, UBIQUITIN, RPS3A1, and RPS3A2 were tested for suitability as reference genes in the five development stages of seeds, leaves, and stems. qRT-PCR was performed using the primers listed in Table S8 to evaluate the expression variation of these candidates across seeds and vegetative tissues. The average threshold $\left(C_{\mathrm{T}}\right)$ values of the candidate genes ranged from 17.25 to 23.66 in seeds and vegetative tissues (Table S9). The coefficient of variation $(\mathrm{CV})$ and $\Delta \mathrm{C}_{\mathrm{T}}$ are parameters used to identify suitable reference genes. The lower the values, the more stable the gene expression. ACTIN1 and ACTIN2 were the most stable genes among the six candidate reference genes. Therefore, ACTIN1 was chosen as a reference gene for this study. The additional experimental details on qRT-PCR are listed in Fig. S3 to demonstrate the reliability of the assay. 

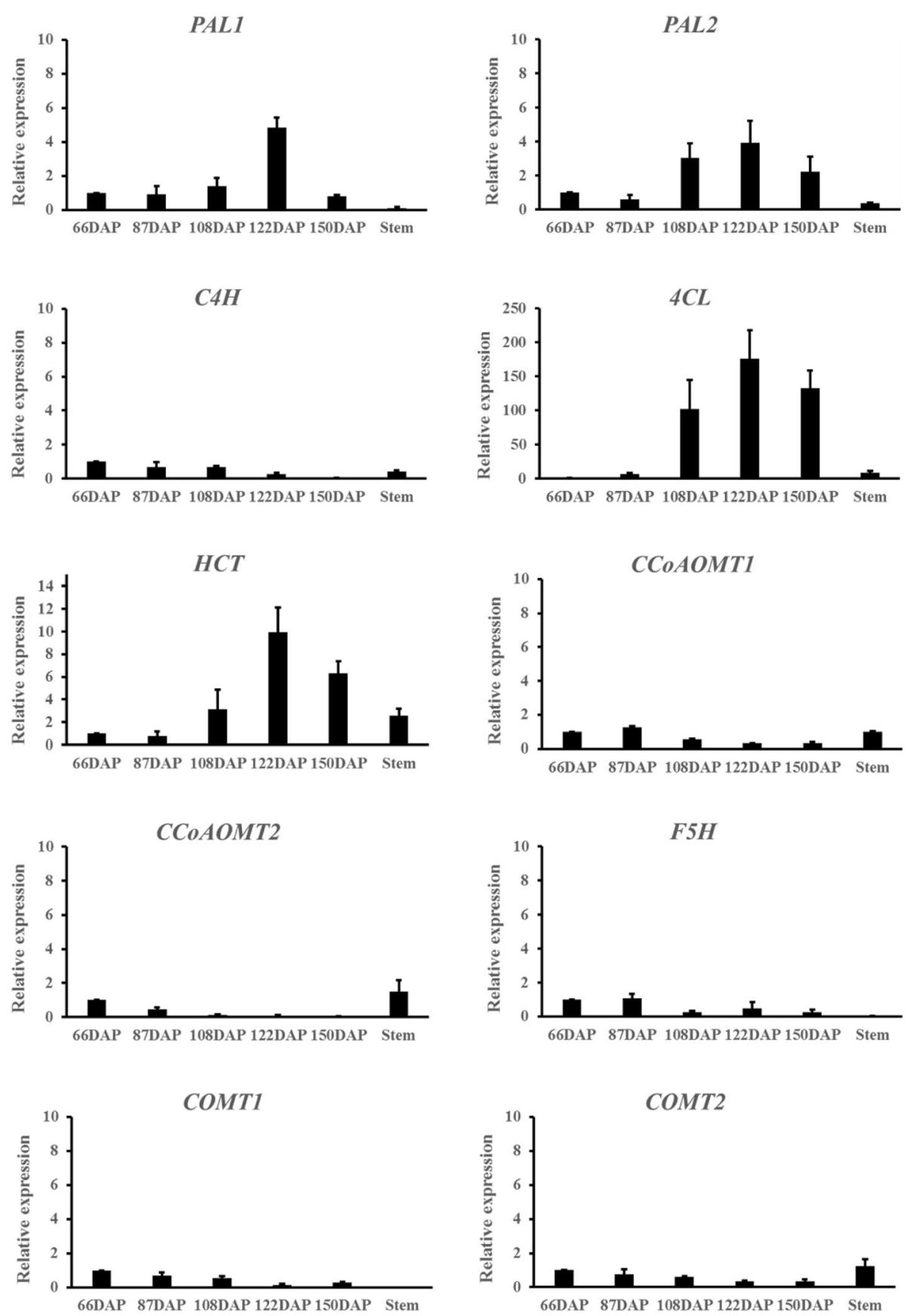

Fig. 7 Validation of lignin-related gene expression in five developmental stages of seed and stems. Expression levels were normalized to expression levels of actin

Consistent with the transcriptomic data, $P A L, 4 C L$, and $H C T$ showed increased expression level as the seed approached maturity (Fig. 7). CCOAOMT displayed relatively high transcript levels at the early stages of seed development and low transcript levels during the later stages. $F 5 H$ and $C O M T$ were also down-regulated during seed development. The results confirm the reliability of the transcriptomic data. Stems displayed relatively high transcript levels of CCOAOMT in contrast to the mature seeds, which suggests that down-regulation of the first lignin methylation gene CCOAOMT is crucial for nonmethylated lignin production.

\section{Discussion}

The structure of orchid seeds is quite simple with its balloon-like seed coat, globular embryo, and lack of 
endosperm. In comparison, most angiosperm seeds have a well-developed embryo and endosperm. Orchid seeds, often referred to as "dust seeds," are typically dispersed by wind [19]. Most species of orchid have difficulty germinating under natural conditions. $P$. armeniacum is one of the most difficult species to propagate, which severely restricts its large-scale production. The factors that inhibit germination are still largely unknown. Plant hormones play essential roles in seed development and germination performance. Abscisic acid (ABA) is necessary for inducing the synthesis of reserve proteins and lipids, as well as the desiccation of developing seeds [20, 21]. In Cypripedium formosanum, an orchid species with low germination rates, ABA was proposed to be the key germination inhibitor [22]. In P. armeniacum seed development, ABA content was increased to $14.4 \mathrm{ng} / \mathrm{g}$ at 122 DAP from $5.6 \mathrm{ng} / \mathrm{g}$ at 66 DAP (Table 1). It is possible that increased levels of $\mathrm{ABA}$ inhibit germination and promote desiccation before the seeds are fully mature. At $150 \mathrm{DAP}$, the ABA level dropped to $2.3 \mathrm{ng} / \mathrm{g}$ with continued decrease on germination rate. Exogenous applications of $\mathrm{ABA}$ or fluridone, an $\mathrm{ABA}$ inhibitor, can change the ABA levels within the seeds, but no significant differences on germination rate was observed (data not shown). Therefore, we believe that other factors may be contributors to the inhibition of germination.

Mature orchid seeds generally have a heavily lignified seed coat that provides protection to the embryo. Several studies attributed lignin accumulation to germination inhibition of mature seeds $[2,6,9]$. In this study, the lignin content was measured during the seed development process to verify whether the lignin content correlates with the germination rate. During the early stages of development, the germination rate gradually increased as the embryo became fully developed, with lignin content maintained at low levels. The germination rate abruptly dropped when the seed lignin accumulated rapidly around 95 DAP. The results showed a negative correlation with lignin amount and germination rate. One possibility is that the lignin-rich seed coat provided mechanical restraint by preventing water and nutrients uptake [4].

The structure and composition of lignin have also been shown to impact the cell wall mechanical properties [23]. In this study, lignins in the Paphiopedilum seeds are composed of $\mathrm{H}$ and $\mathrm{C}$ units, as clearly evident from Py-GC, two-dimensional NMR, and FTIR analysis (Table 2 and Fig. 2), while the lignins in other parts of the Paphiopedilum plant are composed of typical G and $\mathrm{S}$ units. This discovery raised an important question: what is the mechanism for regulating the seed specific deposition of non-methylated lignin?

Five key stages were selected for transcriptome analysis based on the dynamics of lignin accumulation and key anatomical features in embryo development. A total of $104.12 \mathrm{~Gb}$ clean data were obtained from 15 RNA-seq libraries of $66,87,108,122$, and 150 DAP. The assembled data had an average N50 length of $1180 \mathrm{bp}$, which is similar to that in other orchid species, such as Dendrobium catenatum and Apostasia shenzhenica [24, 25]. Phenylpropanoid biosynthesis and phenylalanine metabolism are highly enriched during the rapid lignin accumulation stages. Further DEGs analysis of phenylpropanoid biosynthesis pathway showed that major structural genes were upregulated except for CCOAOMT, F5H, and COMT. Both CCOAOMT and COMT catalyze the O-methylation of the C3 and C5 hydroxyl groups of lignin precursors during G and $\mathrm{S}$ lignin formation. Earlier studies demonstrated low O-methyltransferase (CCoAOMT and COMT) activities in the C-lignin containing seeds of Cleome hasslerianan (C. hasslerianan) [17]. CCoAOMT is the first Omethyltransferase in monolignol pathway. Caffeyl alcohol would be formed if CCoAOMT became depleted or lost its function. Down regulation of CCoAOMT in Pinus radiata introduces caffeyl alcohol into lignification, resulting in low levels of $\mathrm{C}$ units present in the $\mathrm{G}$ lignin dominant tissues [18]. In this study, the low expression level of CCOAOMT, COMT, and $F 5 H$ suggest it is possible that the biochemical basis for the accumulation of non-methylated lignin in seeds. In stem tissues where $\mathrm{G}$ and $\mathrm{S}$ lignins are abundant, the expression levels of CCOAOMT2 and COMT2 are significantly higher than those in the seeds (Fig. 7). Suppression or loss of function of CCOAOMT and COMT in several angiosperm species such as Arabidopsis, alfalfa, poplar, and tobacco did not result in the incorporation of caffeyl alcohol [26-28]. In addition to the methylation genes (CCOAOMT, COMT, and $F 5 H$ ), biosynthesis of $\mathrm{C}$ lignin requires the expression of Cinnamyl alcohol dehydrogenase (CAD) with a preference for the caffealdehyde in the seed coat of Cleome hassleriana [29]. CAD catalyzes the conversion of the corresponding cinnamyl aldehydes to cinnamyl alcohols, which is the last step in the synthesis of monolignols before their polymerization on to the cell walls. However, none of the CAD genes were expressed in a manner consistent with the involvement of C-lignin formation in P. armeniacum.

Other factors may also determine the lignin composition, such as transcriptional regulation or availability of specific monolignol transporters. NAC and MYB families have been identified as regulators of lignin deposition [10, 30, 31]. In our RNA-seq dataset, a total of 944 unigenes that encode TFs associated with 54 families were identified from our assembled transcripts. A total of 40,188, 274, and 247 differentially expressed TFs were found in 87 DAP vs 66 DAP, 108 DAP vs 66 DAP, 122 DAP vs 66 DAP, and 150 vs 66 DAP, respectively 
(Table S6). Instead of the master switches, this study is more focused on the TFs that can specifically regulate the methylation genes, since these TFs can control the accumulation of non-methylated lignin. A few MYBs were identified as potential regulators of CCoAOMT, such as MYB4 and MYB21 (Fig. S4). MYB4 was downregulated as the seed approached maturity. $M Y B 4$ is a positive regulator of $C C O A O M T$ and a negative regulator of $P A L, C 4 H$, and $4 C L$ in Arabidopsis and Pinus tadeda [32, 33]. MYB21 is a negative regulator of CCoAOMT, and the expression level of other structural genes remains unchanged under the influence of MYB21 in Poplar [31]. The expression of these TFs is in agreement with the expression of major structural genes involved in monolignol pathways, implying a potential role in lignin synthesis regulation.

\section{Conclusion}

In summary, the presence of $\mathrm{H}$ and $\mathrm{C}$ lignin in Paphiopedilum seeds exemplifies the flexibility of lignin monomer assembly in nature. Transcriptome profiling revealed the lignin-related candidate genes expression pattern, which clarified the seed-specific monolignol pathways. However, the seed monolignol composition is not consistent even within the same families of Cypripedium, Euphorbiaceae, and Cleomaceae plants, suggesting the feature is not conserved. The difference in the degree of methylation and molecular structure of $\mathrm{C}$ and $\mathrm{H}$ lignin strongly suggests a functional difference compared to typical $\mathrm{G}$ and $\mathrm{S}$ lignin. Future work should focus on linking these unique non-methylated lignin structures to their mechanistic role for seed development and germination.

\section{Methods}

\section{Plant materials and growth conditions}

P. armeniacum S. C. Chen et F. Y. Liu plants were maintained in a glass greenhouse in the South China Botanical Garden, Guangzhou, China. The plants were potted in a substrate of Zhijing stone for orchids under $800 \mu$ mol $\mathrm{m}^{-2} \mathrm{~s}^{-1}$ natural light maintained with a sunshade net. The average temperature and relative humidity ranged from 10 to $32{ }^{\circ} \mathrm{C}$ and $70-98 \%$, respectively. The flowers from three-year-old adult plants were labeled and artificially self-pollinated. Capsules of different developmental stages from 45 DAP to 180 DAP were collected at 7-day intervals from grown plants. Seeds were removed from capsules and immediately frozen in liquid nitrogen.

\section{Seed germination assay}

Seed capsules were surface sterilized as previously described [34]. Seeds were sown on Hyponex N026 medium supplemented with $1.5 \mathrm{~g} / \mathrm{L}$ activated charcoal, $2 \mathrm{~g} / \mathrm{L}$ peptone, $15 \mathrm{~g} / \mathrm{L}$ sucrose, and 5\% coconut water. Germination was scored after the embryo swelled and the testa ruptured.

\section{ABA content}

ABA content was measured as previously described [35]. About $100 \mathrm{mg}$ of seeds were used for ABA quantification by high-performance liquid chromatography-mass spectrometry.

\section{Water content}

Seeds after capsule removal were dried at $100^{\circ} \mathrm{C}$ until constant dry weight was achieved (40-48 h). Water content was expressed as a percentage of fresh weight.

\section{Lignin content and composition}

Lignin content was estimated using acetyl bromide as previously described but with slight modifications [36]. Five (5) $\mathrm{mg}$ of finely ground seed was thoroughly extracted with ethanol/toluene (1:1) until the extracts no longer absorbed UV light at $280 \mathrm{~nm}$. The dried samples were placed into loosely capped glass tubes containing 1 $\mathrm{mL}$ of acetyl bromide/acetic acid (1:3) and incubated at $70^{\circ} \mathrm{C}$ for $30 \mathrm{~min}$. The samples were then cooled in an ice bath and mixed with $0.9 \mathrm{~mL}$ of $2 \mathrm{M} \mathrm{NaOH}, 5 \mathrm{~mL}$ glacial acetic acid, and $0.1 \mathrm{~mL} 7.5 \mathrm{M}$ hydroxylamine hydrochloride. The final volume was adjusted to $10 \mathrm{~mL}$ with glacial acetic acid and the absorbance measured at 280 $\mathrm{nm}$ with a microplate reader (Tecan Infinity). A standard curve was generated using alkali lignin (Sigma-Aldrich, $471,003)$ for lignin content calculation.

The chemical composition of lignin was analyzed by Py-GC/MS using a previously described method with some modifications [37]. The pyrolysis was performed on a Pyroprobe 5000 (CDS Analytical Inc.) directly connected to a Shimadzu GCMS-QP2010A equipped with a HP-5MS column $(30 \mathrm{~m} \times 0.25 \mathrm{~mm} \times 0.25 \mathrm{~mm})$. The pyrolysis was carried out at $550^{\circ} \mathrm{C}$. The chromatograph was programmed from $50^{\circ} \mathrm{C}$ to $250^{\circ} \mathrm{C}$ at a rate of $15^{\circ} \mathrm{C} / \mathrm{min}$ and the final temperature was held for $10 \mathrm{~min}$. Helium was used as the carrier gas at a constant flow rate of 1 $\mathrm{mL} / \mathrm{min}$. The mass spectrometer was operated in scan mode and the ion source was maintained at $300^{\circ} \mathrm{C}$. The compounds were identified by comparing their mass spectra with those of the NIST library and those previously reported $[38,39]$. Peak molar areas were used to calculate the lignin degradation products, and the summed areas were normalized. The relative abundance was calculated from the summed peak areas of each unit.

FTIR

The dried samples were embedded in $\mathrm{KBr}$ pellets in the concentration of about $1 \mathrm{mg} / 100 \mathrm{mg} \mathrm{KBr}$. FTIR spectra 
in the range of $4000-400 \mathrm{~cm}^{-1}$ were recorded using a Shimadzu IRAffinity-1S FTIR spectrophotometer. The spectra were recorded in the absorption mode at 64 scans per sample with a resolution of $4 \mathrm{~cm}^{-1}$.

\section{$2 \mathrm{D}^{13} \mathrm{C}-{ }^{1} \mathrm{H}$ heteronuclear single-quantum coherence (HSQC) NMR spectroscopy}

Seeds from 122 DAP were extracted and ball-milled as previously described [40]. The gels were formed using DMSO$\mathrm{d}_{6} /$ pyridine $-\mathrm{d}_{5}$ (4:1) and sonicated until homogenous. The homogeneous solutions were transferred to NMR tubes. HSQC spectra were acquired at $25^{\circ} \mathrm{C}$ using a Bruker Avance-500 MHz. The running conditions and assignment of the spectra were followed as previously described [13].

RNA extraction, library construction, and RNA sequencing The five developmental stages analyzed were $66,87,108$, 122 , and 150 DAP, with three biological replicates per developmental stage. The total RNA was extracted using Column Plant RNAout2.0 (Tiandz Inc., Beijing, China) according to the manufacturer's protocol, which was specifically designed for materials rich in polysaccharides and polyphenolics. Extracted RNA was treated with DNase (Tiandz Inc., Beijing, China) to remove genomic DNA. The RNA quality was validated using agarose gel electrophoresis, Nanodrop One (Nanodrop Technologies Inc., DE, USA), and Agilent 2100 (Agilent Technologies Inc., CA, USA) to confirm the purity, concentration, and integrity, respectively. Library construction and sequencing were performed using Illumina HiSeq4000 platform (Illumina Inc., CA, USA) by Genepioneer Technologies Corporation (Nanjing, China).

\section{De novo assembly, functional annotation of unigenes, and DEGs analysis}

The clean data was generated by removing adaptor sequences, ambiguous reads ('N'>10\%), and low-quality reads (greater than $50 \%$ of bases in a read with a quality value $Q \leq 5)$ using perl script. All sequence data were uploaded into the BioProject database hosted by the National Center for Biotechnology Information (NCBI) under the BioProject PRJNA550294. The transcripts were assembled using Trinity v2.4.0 program with default parameters [41], and gene expression was estimated by applying the fragments per kilobase per million mapped reads (FPKM). Functional annotations were performed using public databases, including the NR [42], Swiss-Prot [43], COG [44], and GO [45]. Differentially expressed genes (DEGs) between libraries were identified as those with the fold change (FC) of the expression level (FC $\geq 2$ or $\mathrm{FC} \leq 0.5$ under $P$-value $\leq 0.05$, FDR $\leq$ $0.05)$. GO enrichment and KEGG enrichment were performed using the obtained DEGs. To identify genes encoding for TFs, all DEGs were compared with protein sequences downloaded from the plant TF database, PlantTFDB, with the E-values threshold of $10^{-10}$.

\section{Verification of gene expression using qRT-PCR}

Samples of RNA-seq were reversed transcribed into cDNA for real-time qPCR validation using GoScript Reverse Transcription System (Promega, CA, USA). The qRT-PCR reactions were performed on ABI 7500 RealTime PCR System (Applied Biosystems, CA, USA) using the SYBR Premix ExTaq Kit (Takara, Dalian, China). Primer sequences are listed in Table S7. The expression level was calculated as $2^{-\Delta \Delta C t}$ and normalized to the $\mathrm{Ct}$ values of $P$. armeniacum Actin (TRINITY_DN40678_ c2_g1).

\section{Phylogenetic analysis}

The phylogenetic trees were constructed using maximum likelihood method with of MEGA 7 software (Molecular Evolutionary Genetics Analysis version 7.0) with 1000 bootstrap replicates. Analysis of C4H, C3H, F5H, COMT, HCT, and CSE were processed together because at least four taxa are needed for bootstrapping.

\section{Statistical analysis}

Statistical analysis was performed using Student's $t$-test as indicated in the figure legends. All experiments were performed on independently grown biological replicates. All values represent the mean \pm SD.

\section{Supplementary information}

Supplementary information accompanies this paper at https://doi.org/10. 1186/s12864-020-06931-1.

Additional file 1: Figure S1. (A) Correlation indices between different samples. (B) Principal component analysis performed on the 15 samples. A: 65 DAP, B: 87 DAP, C: 108 DAP, D: 122 DAP, E:150 DAP. Figure S2.

Functional annotations of the unigenes of $P$. armeniacum seed transcriptome. (A) NR annotated species distribution map similar to the Paphiopedilum armeniacum transcriptome. Dendrobium catenatum shows the highest similarity. (B) GO function annotation. The most abundant functions are binding and catalytic activity in terms of molecular function and metabolic process and cellular process in terms of biological process. Figure S3. Additional data for qPCR assays. (A) The quality of RNA used for qPCR assessed by agarose gel electrophoresis. 1-4: 66 DAP, 5-8:87 DAP, 9-12: 108 DAP, 13-16: 122 DAP, 17-20: 150 DAP. Lanes 1 and 2 are the 285 and 185 RNA bands. (B) Quantification of RNA used for GPCR estimated by Nanodrop One and Agilent 2100 Bioanalyzer. (C) Melt curve from qPCR of PAL1, PAL2, C4H, 4CL, HCT, CCOAOMT1, CCOAOMT2, F5H, COMT1, and COMT2 genes. The single peak observed presented the pure and single amplicon resulted from the assay. Figure S4. (A) Distribution of differentially expressed transcription factors (TFs); (B) Expression profiles of MYBs potentially related to lignin synthesis.

Additional file 2: Table S1. Overview of transcriptome sequencing and de novo assembly results. Table S2. Overview of transcriptome assembly showing length distribution of transcript and unigene. Table S3. Summary of functional annotation of contigs from BLAST searches against public databases. Table S4. KEGG enrichment analysis list. Table S5. Lignin related genes with RPKM values. Table S6. Differentially expressed transcription factors (TFs) list. Table S7. Primers used for qRTPCR. Table S8. Primers used in the reference genes selection. Table S9. 
Average $\mathrm{Ct}, \Delta \mathrm{C}_{\mathrm{T}}$, and coefficient of variation (CV) values used for the reference genes selection. The average values are shown for at least three replicates per gene and tissue type. Table S10. CDS sequences for monolignol biosynthetic genes.

\section{Abbreviations}

P. armeniacum: Paphiopedilum armeniacum; Py-GC/MS: Pyrolysis-gas chromatography; DAP: Days after pollination; FTIR: Fourier transform infrared spectroscopy; DEG: Differentially expressed genes; NR: Non-redundant protein sequences; GO: Gene Ontology; COG: The Clusters of Orthologous Groups; KEGG: Kyoto Encyclopedia of Genes and Genomes; FDR: False Discovery Rate; PAL: Phenylalanine ammonia lyase; COMT: Caffeic acid Omethyltransferase; CCOAOMT: Caffeoyl-CoA 3-O-methyltransferase; TFs: Transcription factors

\section{Acknowledgements}

The authors would like to thank Yunfei Yuan for assistance with NMR experiments, Yuying Yin, Chuangxue Mao, and Sha Deng for assistance with plant growth and pollination, and Jeemeng Lao for the linguistic editing and proofreading during the preparation of this manuscript.

\section{Authors' contributions}

$L F, K W$ and $S Z$ conceived the research program and designed research. LF, $X X, J L, F Z$, JY and $Y L$ performed research. KW, ML, XZ, GM, FL and SZ analyzed the data. LF, XX, KW and SZ wrote the manuscript. AZ revised this manuscript. All authors read and approved the final manuscript.

\section{Funding}

This work was funded by National Natural Science Foundation of China (31902062), National Key Research and Development Program of China (2016YFC0503104), Guangdong Key Technology Research and Development Program (2018B020202001, 2017A020208036, 2017B090901050), Natural Science Foundation of Guangdong Province (2018A030313686) and Guangdong Modern Agricultural Industry Technology System Program (2018LM2176, 2018LM1142), Biological Resources Program, Chinese Academy of Sciences (KFJ-BRP-007), Guangzhou Science and Technology Program (201904010305),Guangdong Provincial Key Laboratory of Applied Botany, South China Botanical Garden, Chinese Academy of Sciences (AB2018002, AB2018026). The Project was also supported by Program from Core Botanical Gardens, Chinese Academy of Sciences. The funding bodies played no role in the design of the study and collection, analysis, and interpretation of data and in writing of the manuscript.

\section{Availability of data and materials}

All data generated or analyzed during this study are included in this published article and the supplementary information files. The sequence data was deposited at NCBI database under the BioProject PRJNA550294.

\section{Ethics approval and consent to participate}

Not Applicable.

\section{Consent for publication}

Not Applicable.

\section{Competing interests}

The authors declare that they have no competing interests.

\section{Author details}

${ }^{1}$ Guangdong Provincial Key Laboratory of Applied Botany, South China Botanical Garden, Chinese Academy of Sciences, Guangzhou 510650, China. ${ }^{2}$ University of Chinese Academy of Sciences, Beijing 100049, China. ${ }^{3}$ Independent Researcher, Guangzhou 510555, China. ${ }^{4}$ College of Life Sciences, Nanjing Agricultural University, Nanjing 210095, Jiangsu, China. ${ }^{5}$ Environmental Horticulture Research Institute, Guangdong Academy of Agricultural Sciences, Guangzhou 510640, China. ${ }^{6}$ Key Laboratory of South China Agricultural Plant Molecular Analysis and Gene Improvement, South China Botanical Garden, Chinese Academy of Sciences, Guangzhou 510650, China.
Received: 7 August 2019 Accepted: 20 July 2020

Published online: 29 July 2020

\section{References}

1. CITES. http://www.cites.org/eng/app/appendices.php. Appendices I, II and III. (2015). Accessed 26 Mar 2019.

2. Zeng $\mathrm{S}$, et al. In vitro propagation of Paphiopedilum orchids. Crit Rev Biotechnol. 2016;36:521-34.

3. Zhang $Y$, et al. Embryo development in association with asymbiotic seed germination in vitro of Paphiopedilum armeniacum SC Chen et FY Liu. Sci Rep. 2015:5:16356.

4. Steinbrecher T, Leubner-Metzger $G$. The biomechanics of seed germination. J Exp Bot. 2017:68:765-83. https://doi.org/10.1093/jxb/erw428.

5. Tang Y, Zhao D, Meng J, Tao J. EGTA reduces the inflorescence stem mechanical strength of herbaceous peony by modifying secondary wall biosynthesis. Horticulture Research. 2019;6:36.

6. Pierce S, Spada A, Caporali E, Ceriani RM, Buffa G. Enzymatic scarification of Anacamptis morio (Orchidaceae) seed facilitates lignin degradation, water uptake and germination. Plant Biol. 2018;6:36.

7. Yeung EC. A perspective on orchid seed and protocorm development. Bot Stud. 2017:58:33.

8. Pierce $\mathrm{S}$, Cerabolini B. Asymbiotic germination of the White Mountain orchid (Pseudorchis albida) from immature seed on media enriched with complex organics or phytohormones. Seed Sci Technol. 2011;39: 199-203.

9. Barsberg S, Rasmussen HN, Kodahl N. Composition of Cypripedium calceolus (Orchidaceae) seeds analyzed by attenuated total reflectance IR spectroscopy: in search of understanding longevity in the ground. Am J Bot. 2013;100:2066-73

10. Vanholme R, Demedts B, Morreel K, Ralph J, Boerjan W. Lignin biosynthesis and structure. Plant Physiol. 2010;153:895-905.

11. Chen F, et al. Novel seed coat lignins in the Cactaceae: structure, distribution and implications for the evolution of lignin diversity. Plant J. 2013;73:201-11.

12. Barsberg ST, Lee Y-I, Rasmussen HN. Development of C-lignin with G/Slignin and lipids in orchid seed coats-an unexpected diversity exposed by ATR-FT-IR spectroscopy. Seed Sci Res. 2018;28:41-51.

13. Chen F, Tobimatsu Y, Havkin-Frenkel D, Dixon RA, Ralph J. A polymer of caffeyl alcohol in plant seeds. Proc Natl Acad Sci. 2012;109:1772-7. https://doi.org/10.1073/pnas.1120992109.

14. Xie $\mathrm{M}$, et al. Regulation of lignin biosynthesis and its role in growth-defense tradeoffs. Front Plant Sci. 2018;9:1427.

15. Hao Z, Mohnen D. A review of xylan and lignin biosynthesis: foundation for studying Arabidopsis irregular xylem mutants with pleiotropic phenotypes. Crit Rev Biochem Mol Biol. 2014;49:212-41.

16. Stone ML, et al. Reductive catalytic fractionation of C-lignin. ACS Sustainable Chemistry. 2018;6:11211-8.

17. Tobimatsu Y, et al. Coexistence but independent biosynthesis of catechyl and guaiacyl/syringyl lignin polymers in seed coats. Plant Cell. 2013;25: 2587-600.

18. Wagner A, et al. CCOAOMT suppression modifies lignin composition in Pinus radiata. Plant J. 2011:67:119-29.

19. Barthlott, W., Große-Veldmann, B., Korotkova, N. J. A. s. e. m. s. T. N. y. R. M., editores. Berlin: Botanic Garden \& Berlin-Englera, B. M. Orchid seed diversity. (2014).

20. Kinderen G. Abscisic acid in terrestrial orchid seeds: a possible impact on their germination. Lindleyana. 1987;2:84-7.

21. Nambara E, et al. Abscisic acid and the control of seed dormancy and germination. Seed Sci Res. 2010;20. https://doi.org/10.1017/ S0960258510000012.

22. Lee $\mathrm{Yl}$, Chung MC, Yeung EC, Lee N. Dynamic distribution and the role of abscisic acid during seed development of a lady's slipper orchid, Cypripedium formosanum. Ann Bot. 2015;116. https://doi.org/10.1093/aob/ mcv079.

23. Özparpucu M, et al. Unravelling the impact of lignin on cell wall mechanics: a comprehensive study on young poplar trees downregulated for CINNAM YL ALCOHOL DEHYDROGENASE (CAD). Plant J. 2017:91:480-90.

24. Zhang $L$, et al. Origin and mechanism of crassulacean acid metabolism in orchids as implied by comparative transcriptomics and genomics of the carbon fixation pathway. Plant J. 2016;86:175-85. 
25. Zhang G-Q, et al. The Dendrobium catenatum Lindl. genome sequence provides insights into polysaccharide synthase, floral development and adaptive evolution. Scientific reports. 2016;6:19029.

26. Zhong R, Morrison WH, Himmelsbach DS, Poole FL, Ye Z-H. Essential role of caffeoyl coenzyme a O-methyltransferase in lignin biosynthesis in woody poplar plants. Plant Physiol. 2000;124:563-78.

27. Marita JM, et al. Structural and compositional modifications in lignin of transgenic alfalfa down-regulated in caffeic acid 3-0-methyltransferase and caffeoyl coenzyme a 3-0-methyltransferase. Phytochemistry. 2003;62:53-65.

28. Do C-T, et al. Both caffeoyl coenzyme a 3-O-methyltransferase 1 and caffeic acid O-methyltransferase 1 are involved in redundant functions for lignin, flavonoids and sinapoyl malate biosynthesis in Arabidopsis. Planta. 2007;226: 1117-29.

29. Zhuo C, et al. Enzymatic basis for C-lignin monomer biosynthesis in the seed coat of Cleome hassleriana. Plant J. 2019;99:506-20.

30. Zhao Q, Dixon RA. Transcriptional networks for lignin biosynthesis: more complex than we thought? Trends Plant Sci. 2011;16:227-33.

31. Karpinska B, et al. MYB transcription factors are differentially expressed and regulated during secondary vascular tissue development in hybrid aspen. Plant Mol Biol. 2004;56:255-70.

32. Jin $\mathrm{H}$, et al. Transcriptional repression by AtMYB4 controls production of UVprotecting sunscreens in Arabidopsis. EMBO J. 2000;19:6150-61.

33. Patzlaff $A$, et al. Characterisation of a pine MYB that regulates lignification. Plant J. 2003:36:743-54

34. Zeng S, et al. Asymbiotic seed germination, seedling development and reintroduction of Paphiopedilum wardii Sumerh., an endangered terrestrial orchid. Sci Hortic. 2012;138:198-209.

35. Pan X, Welti R, Wang X. Quantitative analysis of major plant hormones in crude plant extracts by high-performance liquid chromatography-mass spectrometry. Nat Protoc. 2010;5:986.

36. Fang $L$, et al. Loss of inositol phosphorylceramide sphingolipid mannosylation induces plant immune responses and reduces cellulose content in Arabidopsis. Plant Cell. 2016;28:2991-3004.

37. Del Río JC, et al. Structural characterization of wheat straw lignin as revealed by analytical pyrolysis, 2D-NMR, and reductive cleavage methods. J Agric Food Chem. 2012;60:5922-35.

38. Del Río JC, Gutiérrez A. Chemical composition of abaca (Musa textilis) leaf fibers used for manufacturing of high quality paper pulps. J Agric Food Chem. 2006;54:4600-10.

39. Ralph J, Hatfield RD. Pyrolysis-GC-MS characterization of forage materials. J Agric Food Chem. 1991;39:1426-37.

40. Kim H, Ralph J. Solution-state 2D NMR of ball-milled plant cell wall gels in DMSO-d6/pyridine-d5. Org Biomol Chem. 2010;8:576-91.

41. Haas BJ, et al. De novo transcript sequence reconstruction from RNA-seq using the trinity platform for reference generation and analysis. Nat Protoc. 2013;8:1494

42. Deng $\mathrm{Y}$, et al. Integrated nr database in protein annotation system and its localization. Comput Eng. 2006:32:71-4.

43. Apweiler R, et al. UniProt: the universal protein knowledgebase. Nucleic Acids Res. 2004:32:D115-9.

44. Tatusov RL, Galperin MY, Natale DA, Koonin EV. The COG database: a tool for genome-scale analysis of protein functions and evolution. Nucleic Acids Res. 2000;28:33-6.

45. Consortium, G. O. The Gene Ontology (GO) database and informatics resource. Nucleic Acids Res. 2004:32:D258-61.

\section{Publisher's Note}

Springer Nature remains neutral with regard to jurisdictional claims in published maps and institutional affiliations.

Ready to submit your research? Choose BMC and benefit from:

- fast, convenient online submission

- thorough peer review by experienced researchers in your field

- rapid publication on acceptance

- support for research data, including large and complex data types

- gold Open Access which fosters wider collaboration and increased citations

- maximum visibility for your research: over $100 \mathrm{M}$ website views per year

At $\mathrm{BMC}$, research is always in progress.

Learn more biomedcentral.com/submissions 